\title{
An Optimization of Redundant Measurements Location for Thermal Capacity of Power Unit Steam Boiler Calculations using Data Reconciliation Method
}

\author{
Marcin SZEGA \\ Grzegorz Tadeusz NOWAK \\ Institute of Thermal Technology, Silesian University of Technology, 44-100 Gliwice, Konarskiego 22 \\ marcin.szega@polsl.pl,grzegorz.t.nowak@polsl.pl
}

Summary. The optimization of a location of redundant measurements under varying loads for steam boiler of a supercritical power unit using the generalized method of data reconciliation has been carried out. The method of weighted objectives has been applied as a method of optimization. This method reduce the weighted multi-criteria optimization task to task one-dimensional. Measurement values have been determined by numerical experiment and the Monte Carlo method for the designed redundant measurements system. For this purpose, a mathematical simulation model of a supercritical steam power unit with power rating of $900 \mathrm{MW}$ in the Thermoflex program has been worked out. In the optimization calculations of location of redundant measurements as an objective functions minimizing the relative standard deviation of a boiler thermal capacity and maximizing the Kullback-Leibler divergence have been accepted. In the calculation the measurements were taken into account, which can be located in the water-steam system of the boiler and in the high-pressure heat recovery steam supercritical power unit. The results of calculations confirm the influence of the number of redundant measurements and places of their location in the thermal system of the boiler on the accepted criteria of optimization. Increasing the number of redundant measurements, in terms of the data reconciliation method, leads to decrease the relative standard deviation of the thermal capacity of the boiler and increase the value of KullbackLeibler divergence, i.e.; decrease the information entropy of the measuring system.

Key words: Data reconciliation, steam boiler, optimization of measurements location, numerical simulation.

\section{Introduction}

Currently energy conversion processes occurring in the contemporary steam power plants cannot be realized without the automatic supervision and ability to influence of their course. Modern power units are equipped with complex automation and control systems necessary for their proper operation. Increasing the nominal power of a power units and the use of supercritical steam parameters results in complexity of their thermal system [2,9]. For the safe operation of a supercritical coal-fired steam power units a sufficient number of measurements, concerning the technical condition of their equipment and running the processes of energy conversion, is required. Besides of measurement information associated with the control process, the measurement information concerning the supervision of operation has been 
significantly increased. Currently it enables the usage of a computer systems for decision support in terms of technical control operation and application of advanced methods of engineering analysis. An indispensable element of such systems should be an advanced validation of measurements data from distributed control systems using data reconciliation methods in case of measurements redundancy $[1,9,13,17]$. Moreover the data reconciliation method should be used in the case of application measurements data in the identification of empirical models, e.g. regression or artificial neural networks [4]. Also diagnosis of complex energy systems as presented e.g. in [11,12] requires reliable and reconciled operational measurements and unknown values. Only credible measurements data and calculated parameters should be used in this type of applications.

The generalized method of data reconciliation $[6,8]$ could be used at the design stage of redundant measurements system for newly built power units. Number of redundant measurements and their location in the thermal system of power units can be optimized from the used criterion point of view. This criterion could be the minimization of uncertainty of the selected parameter which characterize the energy conversion process. Moreover another criterion can be determination of an extremum of parameters which describes in a comprehensive way the measurements system quality after validation his measurements.

The optimization of a location of redundant measurements under varying loads for steam boiler of a supercritical power unit using the generalized method of data reconciliation has been carried out. The method of weighted objectives has been applied as a method of optimization. This method reduce the weighted multi-criteria optimization task to onedimensional task. The value of the criterion function in this method is the value obtained from the optimization calculation of the considered measurements location configuration for a given number of redundant measurements and for a given power unit load. It has been assumed that for the determination of weights of the objective functions the ordered diagram of real working of power unit will be used.

Measurement values have been determined by numerical experiment and the Monte Carlo method for the designed redundant measurements system. For this purpose, a mathematical simulation model of a supercritical steam power unit with a rated power of $900 \mathrm{MW}$ in the Thermoflex program [16] has been worked out. Using simulation model a calculations for different loads of power unit have been performed. In the optimization calculations of location of redundant measurements as an objective functions minimizing the relative standard deviation of a boiler thermal capacity and maximizing the Kullback-Leibler divergence have been accepted [3]. This divergence is the criterion which describes the quality of redundant measurement system as a whole [10]. In the calculation the measurements were taken into account, which can be located in the water-steam system of the boiler and in the high-pressure heat recovery steam supercritical power unit.

The proposed algorithm consists in searching of vector of objective function values obtained from all possible solutions of the measurements configuration location in the thermal system of the boiler. The results of calculations confirm the influence of the number of redundant measurements and places of their location in the thermal system of the boiler on the accepted criteria of optimization. Increasing the number of redundant measurements, in terms of the data reconciliation method, leads to decrease the relative standard deviation of the 
thermal capacity of the boiler and increase the value of Kullback-Leibler divergence, i.e.; decrease the information entropy of the measuring system.

\section{Principle of data reconciliation}

Evaluation of the energy process is carried out by means of its measurements. In reality there are no error-free measurements. The results of measurements contain errors due to inaccuracy of the applied method of measurements, failures of the device or in the signal processing. Such errors are then passed to calculations of unknown values (quantities that are not measured). In thermal engineering in most cases the number of balance equations is larger than the number of unknown values. Hence the surplus equations are not fulfilled because the substance and energy balance equations are not reconciled. The application of the data reconciliation method permits calculations of the measurement corrections so that the all balance equations are fulfilled.

Data reconciliation can be mathematically expressed as a constrained weighted leastsquares optimization problem [7,17]:

$$
\begin{gathered}
\min \left\{\sum_{i=1}^{m}\left(\frac{\hat{x}_{i}-x_{i}}{\sigma_{i}}\right)^{2}\right\} \\
g_{l}\left(\hat{x}_{i}, \hat{y}_{j}\right)=0 \text { fubject to } \quad l=1, \ldots, r
\end{gathered}
$$

The objective function (1) defines the total weighted sum of measurements corrections squares, whereas equation (2) defines the set of mathematical model constrains. In the thermal engineering these constrains are generally mass and energy balances. Data reconciliation in thermal analysis permits to achieve the following aims $[6,7,9,17,18]$ :

- calculation of the most reliable thermal measurements values,

- unique solution of the most probable unknown quantities in thermal processes,

- an assessment of the accuracy of the corrected results of measurements and of calculated unknown quantities,

- a reduction of uncertainty of measured quantities,

- the control of fulfilling of the assumed measurements uncertainty.

\section{Simulation model of the thermal system of power unit}

As previously specified, for the designed redundant measurements system, measurement values by means of numerical experiment have been determined. For this purpose, a mathematical simulation model of a supercritical steam power unit with a rated power of $900 \mathrm{MW}$ in the Thermoflex program has been worked out. Thermoflex is a simulation program dedicated for simulation of power units [16]. Simulation calculations in this program was divided into three parts. In the first one the structure of the power unit is build and values of thermodynamics parameters in particular points of thermal system are 
assumed, for example: live and reheated steam parameters, pressure in the condenser, ambient parameters, electric power of the turbo-generator, etc. The results of calculations obtained from simulation model were verified by examples presented in the literature and industrial applications. The next step was to transfer this model into off-designed mode which allowed to simulate different loads of power unit and observe the behavior depending on the change of electric power of the turbo-generator. In the last part of simulation the calculations for various loads of the steam power unit have been carried out. The five loads were considered: 60, 70, 80,90 and 100 percentage of power unit nominal load. Results of this simulation are presented in Table 1.

Table 1. Selected output data for the simulation calculations

\begin{tabular}{|l|c|c|c|c|c|c|}
\hline \multirow{2}{*}{ Parameters } & \multirow{2}{*}{ Unit } & \multicolumn{5}{c|}{ Load, \% } \\
\cline { 3 - 7 } & & 100 & 90 & 80 & 70 & 60 \\
\hline Gross power & $\mathrm{MW}$ & 900.0 & 810.4 & 720.0 & 630.5 & 539.8 \\
\hline Gross efficiency & $\%$ & 46.84 & 46.46 & 45.87 & 45.00 & 43.92 \\
\hline Net power & $\mathrm{MW}$ & 842.1 & 758.9 & 674.1 & 589.1 & 503.0 \\
\hline Live steam temperature & ${ }^{\circ} \mathrm{C}$ & 650.0 & 649.0 & 649.0 & 649.8 & 648.8 \\
\hline Live steam pressure & $\mathrm{MPa}$ & 30.0 & 26.9 & 23.9 & 21.0 & 18.2 \\
\hline $\begin{array}{l}\text { Reheated steam } \\
\text { temperature }\end{array}$ & ${ }^{\circ} \mathrm{C}$ & 670.0 & 670.0 & 670.0 & 669.2 & 669.1 \\
\hline Reheated steam pressure & $\mathrm{MPa}$ & 5.9 & 5.4 & 4.8 & 4.2 & 3.7 \\
\hline Feed water temperature & ${ }^{\circ} \mathrm{C}$ & 309.0 & 304.0 & 298.0 & 291.0 & 284.0 \\
\hline
\end{tabular}

Considered part of the thermal system of power unit, which is the water-steam boiler system with a high-pressure regeneration and high-pressure part of the steam turbine with marked measuring points is shown in the Fig. 1. In the scheme of considered thermal system (Fig. 1) redundant measurements from the data reconciliation method point of view are shown in squares.

\section{Conditional equations of the data reconciliation task}

As described above the data reconciliation task requires the formulation of the set of mathematical model constrains. According to the scheme for the analyzed water-steam system of the boiler presented in the Fig.1, the mass and energy balances equations in the steady state of steam boiler operation can be formulated. Total number of conditional equations is equal to $r=13$. Mass and energy balances are illustrated below.

- mass balance of the live steam:

$$
\dot{m}_{(1)}=\dot{m}_{(13)}+\dot{m}_{(14)}
$$

- mass balance of the re-superheated steam: 


$$
\dot{m}_{(4)}=\dot{m}_{(7)}+\dot{m}_{(10)}
$$

- mass balance of the high pressure part of the steam turbine

$$
\dot{m}_{(1)}=\dot{m}_{(42)}+\dot{m}_{(39)}+\dot{m}_{(19)}+\dot{m}_{(7)}
$$

- mass balance of the condensate from heat exchanger RHE2:

$$
\dot{m}_{(26)}=m_{(39)}+\dot{m}_{(19)}
$$

- mass balance of the condensate from heat exchanger RHE1:

$$
\dot{m}_{(24)}=m_{(39)}+\dot{m}_{(35)}+\dot{m}_{(19)}
$$

- mass balance of the feed water mixing point before the boiler:

$$
\dot{m}_{(13)}+\dot{m}_{(14)}=\dot{m}_{(33)}+\dot{m}_{(34)}+\dot{m}_{(43)}
$$

- energy balance of the feed water mixing point before the boiler:

$$
\dot{m}_{(20)} h\left(t_{(46)}, p_{(15)}\right)+\dot{m}_{(43)} h\left(t_{(44)}, p_{(45)}\right)=\dot{m}_{(1)} h\left(t_{(16)}, p_{(15)}\right)
$$

- mass balance of the mixing point of the feed water behind the desuperheater DSH:

$$
\dot{m}_{(20)}=\dot{m}_{(33)}+\dot{m}_{(34)}
$$

- energy balance of the feed water mixing point behind the desuperheater DSH:

$$
\dot{m}_{(33)} h\left(t_{(38)}, p_{(15)}\right)+\dot{m}_{(34)} h\left(t_{(32)}, p_{(15)}\right)=\dot{m}_{(20)} h\left(t_{(46)}, p_{(15)}\right)
$$

- energy balance of the heat exchanger RHE1:

$$
\begin{gathered}
{\left[\dot{m}_{(35)} h\left(t_{(30)}, p_{(29)}\right)+\dot{m}_{(26)} h\left(t_{(25)}, p_{(17)}\right)-\dot{m}_{(24)} h\left(t_{(23)}, p_{(29)}\right)\right] \eta_{H E}=} \\
=\dot{m}_{(20)}\left[h\left(t_{(27)}, p_{(22)}\right)-h\left(t_{(21)}, p_{(22)}\right)\right]
\end{gathered}
$$

- energy balance of the heat exchanger RHE2: 


$$
\begin{gathered}
{\left[\dot{m}_{(35)} h\left(t_{(30)}, p_{(29)}\right)+\dot{m}_{(26)} h\left(t_{(25)}, p_{(17)}\right)-\dot{m}_{(24)} h\left(t_{(23)}, p_{(29)}\right)\right] \eta_{H E}=} \\
=\dot{m}_{(20)}\left[h\left(t_{(27)}, p_{(22)}\right)-h\left(t_{(21)}, p_{(22)}\right)\right]
\end{gathered}
$$

- energy balance of the heat exchanger RHE3:

$$
\dot{m}_{(39)}\left[\left(t_{(40)}, p_{(41)}\right)-h\left(t_{(31)}, p_{(41)}\right)\right] \eta_{H E}=\dot{m}_{(20)}\left[h\left(t_{(32)}, p_{(15)}\right)-h\left(t_{(28)}, p_{(22)}\right)\right]
$$

- energy balance of the desuperheater DSH:

$$
\dot{m}_{(35)}\left[\left(t_{(36)}, p_{(37)}\right)-h\left(t_{(30)}, p_{(29)}\right)\right] \eta_{H E}=\dot{m}_{(33)}\left[h\left(t_{(38)}, p_{(15)}\right)-h\left(t_{(32)}, p_{(15)}\right)\right]
$$

Thermal capacity of the steam boiler results from the formula:

$$
\begin{aligned}
& \dot{Q}_{S B}=\dot{m}_{(1)}\left[h\left(t_{(3)}, p_{(3)}\right)-h\left(t_{(16)}, p_{(15)}\right)\right]+\dot{m}_{(4)} h\left(t_{(6)}, p_{(5)}\right)-\dot{m}_{(7)} h\left(t_{(9)}, p_{(8)}\right)+ \\
& -\dot{m}_{(10)} h\left(t_{(12)}, p_{(11)}\right)+\dot{m}_{(43)}\left[h\left(t_{(44)}, p_{(45)}\right)-h\left(t_{(21)}, p_{(22)}\right)\right]+ \\
& +\dot{m}_{(47)}\left[h\left(t_{(50)}, p_{(51)}\right)-h\left(t_{(48)}, p_{(49)}\right)\right]
\end{aligned}
$$

Subscripts in the balance equations refer to the measurement points shown in the scheme of the considered thermal system of the steam boiler (Fig. 1).

Standard uncertainties of the measurements of pressure, temperature and mass flow for the data reconciliation calculations on the base of best practice in industrial measurement equipment and $[14,15,18]$ have been assumed.

\section{Optimization of a redundant measurements location}

As previously illustrated, as a result of application of the data reconciliation method the reconciled measurements data and reduction of its uncertainty have been achieved. For optimal location of redundant measurements in the water-steam boiler and the high-pressure heat regeneration system of power unit as a criterion of optimization, the minimization of uncertainty of the steam boiler thermal capacity can be used. Because in the data reconciliation calculations all measurements data are corrected, it is convenient for the analysis to accept the relative standard deviation of the steam boiler thermal capacity $\operatorname{RSD}\left(\dot{Q}_{S B}\right)$. Minimum of the value of $\operatorname{RSD}\left(\dot{Q}_{S B}\right)$ can be criterion of the optimal location of an additionally redundant measurements in the measurements system of the boiler and highpressure heat regeneration system of power unit. Objective function of such described optimization task can be defined as follows: 


$$
\left.\begin{array}{c}
R S D\left(\dot{Q}_{S B}\right)_{k}=\min \left\{R S D\left(\dot{Q}_{S B}\right)_{k j}\right\} \\
f o r \\
k=1, \ldots, n \\
j=1, \ldots, L(k)
\end{array}\right\}
$$

For the assessment of the measurements system as a whole the Kullback-Leibler divergence has been applied [3]. Quality of a redundant system of measurements after introduction of new redundant measurement should be evaluated by applying criterion, which permits to measure the reliability increase of a measurements - both values of measurements as well as its uncertainties. It has been assumed that measurements system of thermal process represents a signals system of communication, which can be able to send the information about thermodynamic parameters of thermal process. For this assumption the entropy of information can be applied as an assessment criterion of quality of measurements system. In information theory, entropy is a measure of the uncertainty which is associated with a random variable [5]. In probability and information theory also concept of a relative entropy called Kullback-Leibler divergence has been introduced [3]. The Kullback-Leibler divergence is a non-symmetric measure of the difference between two probability distributions. Typically one of them represents the true distribution of data, observations, or a precise calculated theoretical distribution. Whereas the other distribution typically represents a theory, model, description or approximation of data.

Introduction the variance-covariance matrices property in data reconciliation method the Kullback-Leibler divergence (in bits) has the following form [10]:

$$
D_{K L}(\hat{N} \| N)=\frac{1}{2 \cdot \ln (2)}\left\{\ln \left[\prod_{i=1}^{m}\left(\frac{\sigma_{i}}{\hat{\sigma}_{i}}\right)^{2}\right]+\sum_{i=1}^{m}\left(\frac{\hat{x}_{i}-x_{i}}{\sigma_{i}}\right)^{2}+u-r\right\}
$$

In an assessment of increase of a measurements data reliability, in principle, we are not interested in absolute value of information entropy, but only in the decrease of this entropy from state of raw measurements data to state of reconciled measurements. Hence, assuming that distributions $N$ and $\hat{N}$ concerns respectively raw and reconciled measurements data the calculation of decrease of information entropy of measurements data after application of data reconciliation algorithm can be determined by use of formula (18). In this case the KullbackLeibler divergence can constitute the criterion of an assessment of increase of a measurements data reliability in a redundant system of measurements of thermal systems.

Minimum of the entropy information of the reconciled measurements value, that is maximum of Kullback-Leibler divergence (18) from reconciled measurements to the raw measurements data, can be also criterion of the optimal location of a redundant measurements in the measurements system of the thermal systems. Objective function of such described optimization task can be defined as follows: 


$$
\left.\begin{array}{c}
D_{K L}(\hat{N} \| N)_{k}=\max _{f o r}\left\{D_{K L}(\hat{N} \| N)_{k j}\right\} \\
k=1, \ldots, n \\
j=1, \ldots, L(k)
\end{array}\right\}
$$

The current methodology of optimization of the location of an additional redundant measurements (in the sense of the use of data reconciliation method), the nominal load of the power unit has been assumed [9,10]. It is obvious, however, that due to the changing demand of the electric power in the power system, load of the power units is variable in time. Load variation causes changes of energy carriers flows and their thermodynamics parameters in the power units. A method for optimizing the location of an additional redundant measurements under varying load of power unit has been worked out. The proposed methodology uses information contained in an ordered diagram of real working of power unit. Basing on this diagram of the power unit load, you can determine the time intervals of the selected average load occurrence and carry out the optimization procedure of the additional redundant measurements location for average loads occurring in these intervals. For the relative values of the time intervals this diagram indicates the likelihood of the load value.

The method of weighted objectives has been applied as a method of optimization. This method reduce the weighted multi-criteria optimization task to one-dimensional task. This reduction is being achieved by joining the respective criterion function to a single weighted objective function of the general form:

$$
F(z)=\sum_{i=1}^{q} w_{i} f_{i}(z)
$$

where $w_{i}$ denotes $i$-th weight of the criterion function and fulfills the following criterions:

$$
\begin{gathered}
w_{i} \in[0,1] \\
\sum_{i=1}^{q} w_{i}=1
\end{gathered}
$$

In the form of equation (20), it is evident that the different weight vectors will yield different optimal solution. Hence, it occurs a problem in the selection of appropriate weight values for each criterion functions in order to obtain good quality solutions. In the proposed methodology, the values of the criterion functions are the values obtained from the optimization calculations for the considered configuration for a given number of redundant measurements and for a given load of power unit. The weights of the criterion functions are the probabilities of occurrence of the average load of the power unit resulting from the ordered diagram loads obtained from the power unit real operation. The accepted weights of criterion functions satisfies the conditions (21) and (22) the objective function (20).

Using the measurement of the electric power from the distributed control system of the power unit working in one of the power plant an ordered diagram has been prepared. Basing on this diagram the probabilities of occurrence of a defined generator loads have been determined. The values of the probabilities of generator loads have been determined for five 
load values in the range of 60 to $100 \%$ of nominal load. The calculation results are shown in the Table 2.

Table 2. Probability of power unit turbo-generator load

\begin{tabular}{|l|l|l|}
\hline No. & $\begin{array}{l}\text { The ratio of the average } \\
\text { power in the range of } \\
\text { loads to the power } \\
\text { rating, \% }\end{array}$ & $\begin{array}{l}\text { Value of the } \\
\text { probability of turbo- } \\
\text { generator load }\end{array}$ \\
\hline 1 & 2 & 3 \\
\hline 1 & 60 & 0.305 \\
2 & 70 & 0.051 \\
3 & 80 & 0.052 \\
4 & 90 & 0.083 \\
5 & 100 & 0.509 \\
\hline
\end{tabular}

Calculations of the criterion value of the objective function $f_{i}(z)$ for a given $i$-th power unit load and assumed $p$-th number of redundant measurements according to the developed algorithm described in $[9,10]$ have been carried out. Determining the optimal value of the weighted objective function (20) needs the repetition of $t$-times the developed optimization procedure. In the considered problem the number of optimization criteria is equal to $q=5$ and it concerns the number of assumed values of turbo-generator loads.

For a given number of redundant measurements $p$ and the power unit load in the $i$-th time interval of the ordered diagram we obtain the components values of the objective function (20) in the form of below vector:

$$
\mathbf{f}(p)_{i}=\left[\begin{array}{c}
f_{1}(p)_{i} \\
f_{2}(p)_{i} \\
\vdots \\
f_{L(p)}(p)_{i}
\end{array}\right]
$$

The vector $\mathbf{f}(p)$ has a number of components equal to the total number of measurements configurations $L(p)$ for a given number $p$-th of redundant measurements.

Vector of solutions for all configurations of measurements of the weighted objective function for a given $p$-th number of redundant measurements has the form: 


$$
\mathbf{F}(p)=\left[\begin{array}{c}
F_{1}(p) \\
F_{2}(p) \\
\vdots \\
F_{L(p)}(p)
\end{array}\right]=\sum_{i=1}^{q} w_{i}\left[\begin{array}{c}
f_{1}(p)_{i} \\
f_{2}(p)_{i} \\
\vdots \\
f_{L(p)}(p)_{i}
\end{array}\right]
$$

From the elements of vector $\mathbf{F}(p)$ the value which fulfill the assumed criterion of optimization is being chosen. When the criterion function $f(z)$ is the relative standard deviation of the boiler thermal capacity, namely:

$$
f(z)=R S D\left(\dot{Q}_{S B}\right)
$$

the lowest value from the vector $\mathbf{F}(p)$ is being selected.

If the function of criterion is the Kullback-Leibler divergence, that is:

$$
f(z)=D_{K L}(\hat{N} \| N)
$$

from the vector $\mathbf{F}(p)$ the highest value is being selected.

\section{Example of optimization calculations}

Value of the $\operatorname{RSD}\left(\dot{Q}_{S B}\right)$, as mentioned previously, constitutes the assumed criterion of assessment of uncertainty measurement decrease after data reconciliation. The criterion is depended on the number of a surplus measurements quantities, as well as depended on the location in the analyzed thermal system. The procedure of an optimization calculations requires first of all the identification of potential location for installation of an additional surplus measurements in a thermal system, considering the technical constrains. These potential places determining the maximum number of available redundant measurements in the system. The determined number of redundant measurements (lower than possible maximum) can be installed in measurements system in different configurations. Solution of the optimization task (17) requires determination of the $R S D\left(\dot{Q}_{S B}\right)$ for all available configurations of installation of this measurements in the analyzed thermal system. Number of this installation configurations results from the binomial coefficient. For any set containing $n$ elements, the number of considered $k$-elements subsets is given by the formula:

$$
L(k)=C_{n}^{k}=\left(\begin{array}{l}
n \\
k
\end{array}\right)=\left(\frac{n !}{k !(n-k) !}\right), \text { where } k \leq n, \quad n, k \in N^{+}
$$

For $n$-elements set of all considered additional redundant measurements data, number of all available configurations of their installation in the thermal system will be the sum of configurations $L(k)$ results from the formula: 


$$
L=\sum_{k=1}^{n} C_{n}^{k}=\sum_{k=1}^{n}\left(\begin{array}{l}
n \\
k
\end{array}\right)=\sum_{k=1}^{n}\left(\frac{n !}{k !(n-k) !}\right)
$$

The optimization calculations for previously defined variants of configurations of the additional measurements in the analyzed thermal system on the basis of the algorithm presented in [8] have been carried out.

Number of the configurations of redundant measurements location for each amount of a measurements is calculated by means of formula (27). Column 2 of the Table 3 presents the number of analyzed configurations of an additional redundant measurements locations. Total number of analyzed measurements locations configurations resulting from the formula (28) is $L=8191$. The optimization calculations using the computer program elaborated in Fortran language have been carried out.

Table 3. Results of optimizations calculations

\begin{tabular}{|c|c|c|c|}
\hline $\begin{array}{c}\text { Number of } \\
\text { redundant } \\
\text { measure-- } \\
\text { ments data, } \\
\quad k\end{array}$ & $\begin{array}{c}\text { Number of } \\
\text { configuration of } \\
\text { installation of } \\
\text { redundant } \\
\text { measurements data, } \\
L(k)\end{array}$ & $\begin{array}{l}\text { Sets of the optimal configuration of } \\
\text { redundant measurements data }\end{array}$ & $\begin{array}{l}\text { Optimal values of the } \\
\text { considered variables }\end{array}$ \\
\hline 1 & 2 & 3 & 4 \\
\hline \multirow[t]{2}{*}{$\mathrm{k}=0$} & \multirow[t]{2}{*}{$L(0)=C_{13}^{0}=1$} & $M_{\min R S D}=\varnothing$ & $R S D\left(\dot{Q}_{S B}\right)=4.213 \%$ \\
\hline & & $M_{\max D K L}=\emptyset$ & $D_{K L}=0.00$ bit \\
\hline \multirow[t]{2}{*}{$\mathrm{k}=1$} & \multirow[t]{2}{*}{$L(1)=C_{13}^{1}=13$} & $M_{\min R S D}=\{43\}$ & $R S D\left(\dot{Q}_{S B}\right)=2.362 \%$ \\
\hline & & $M_{\max D K L}=\{46\}$ & $D_{K L}=1.58$ bit \\
\hline \multirow[t]{2}{*}{$\mathrm{k}=2$} & \multirow[t]{2}{*}{$L(2)=C_{13}^{2}=78$} & $M_{\min R S D}=\{4,43\}$ & $R S D\left(\dot{Q}_{S B}\right)=2.112 \%$ \\
\hline & & $M_{\max D K L}=\{4,43\}$ & $D_{K L}=2.50$ bit \\
\hline \multirow[t]{2}{*}{$\mathrm{k}=3$} & \multirow[t]{2}{*}{$L(3)=C_{13}^{3}=286$} & $M_{\min R S D}=\{4,7,43\}$ & $R S D\left(\dot{Q}_{S B}\right)=1.932 \%$ \\
\hline & & $M_{\max D K L}=\{4,7,43\}$ & $D_{K L}=3.57$ bit \\
\hline \multirow[t]{2}{*}{$\mathrm{k}=4$} & \multirow[t]{2}{*}{$L(4)=C_{13}^{4}=715$} & $M_{\min R S D}=\{4,7,26,43\}$ & $R S D\left(\dot{Q}_{S B}\right)=1.846 \%$ \\
\hline & & $M_{\max D K L}=\{4,7,43,46\}$ & $D_{K L}=4.30$ bit \\
\hline \multirow[t]{2}{*}{$\mathrm{k}=5$} & \multirow[t]{2}{*}{$L(5)=C_{13}^{5}=1287$} & $M_{\min R S D}=\{4,7,23,24,43\}$ & $R S D\left(\dot{Q}_{S B}\right)=1.741 \%$ \\
\hline & & $M_{\max D K L}=\{4,7,23,24,43\}$ & $D_{K L}=5.19$ bit \\
\hline \multirow[t]{2}{*}{$\mathrm{k}=6$} & \multirow[t]{2}{*}{$L(6)=C_{13}^{6}=1716$} & $M_{\min R S D}=\{4,7,13,23,24,43\}$ & $R S D\left(\dot{Q}_{S B}\right)=1.691 \%$ \\
\hline & & $M_{\max D K L}=\{4,7,23,24,43,46\}$ & $D_{K L}=6.22$ bit \\
\hline \multirow[t]{2}{*}{$\mathrm{k}=7$} & \multirow[t]{2}{*}{$L(7)=C_{13}^{7}=1716$} & $M_{\min R S D}=\{4,7,23,24,33,34,43\}$ & $\operatorname{RSD}\left(\dot{Q}_{S B}\right)=1.642 \%$ \\
\hline & & $M_{\max D K L}=\{4,7,23,24,39,43,46\}$ & $D_{K L}=6.91$ bit \\
\hline $\mathrm{k}=8$ & $L(8)=C_{13}^{8}=1287$ & $M_{\min R S D}=\{4,7,13,23,24,33,34,43\}$ & $R S D\left(\dot{Q}_{S B}\right)=1.592 \%$ \\
\hline
\end{tabular}




\begin{tabular}{|c|c|c|c|}
\hline & & $M_{\max D K L}=\{4,7,23,24,26,39,43,46\}$ & $D_{K L}=7.50$ bit \\
\hline \multirow[t]{2}{*}{$\mathrm{k}=9$} & \multirow[t]{2}{*}{$L(9)=C_{13}^{9}=715$} & $M_{\min R S D}=\{4,7,13,23,24,26,33,34,43\}$ & $R S D\left(\dot{Q}_{S B}\right)=1.567 \%$ \\
\hline & & $M_{\max D K L}=\{4,7,23,24,34,35,39,43,46\}$ & $D_{K L}=8.21$ bit \\
\hline \multirow[t]{2}{*}{$\mathrm{k}=10$} & \multirow[t]{2}{*}{$L(10)=C_{13}^{10}=286$} & $M_{\min R S D}=\{4,7,13,23,24,26,33,34,43,46\}$ & $R S D\left(\dot{Q}_{S B}\right)=1.547 \%$ \\
\hline & & $M_{\max D K L}=\{4,7,23,24,26,33,34,39,43,46\}$ & $D_{K L}=8.85$ bit \\
\hline \multirow[t]{2}{*}{$\mathrm{k}=11$} & \multirow[t]{2}{*}{$L(11)=C_{13}^{11}=78$} & $M_{\min R S D}=\{4,7,13,23,24,26,33,34,35,43,46\}$ & $R S D\left(\dot{Q}_{S B}\right)=1.535 \%$ \\
\hline & & $M_{\max D K L}=\{4,7,19,23,24,26,33,34,39,43,46\}$ & $D_{K L}=9.46$ bit \\
\hline \multirow[t]{2}{*}{$\mathrm{k}=12$} & \multirow[t]{2}{*}{$L(12)=C_{13}^{12}=13$} & $\begin{array}{l}M_{\min R S D} \\
=\{4,7,13,19,23,24,26,33,34,35,43,46\}\end{array}$ & $R S D\left(\dot{Q}_{S B}\right)=1.532 \%$ \\
\hline & & $\begin{array}{l}M_{\max D K L} \\
=\{4,7,19,23,24,26,33,34,35,39,43,46\}\end{array}$ & $D_{K L}=10.02$ bit \\
\hline \multirow[t]{2}{*}{$\mathrm{k}=13$} & \multirow[t]{2}{*}{$L(13)=C_{13}^{13}=1$} & $\begin{array}{l}M_{\min R S D} \\
=\{4,7,13,19,23,24,26,33,34,35,39,43,46\}\end{array}$ & $R S D\left(\dot{Q}_{S B}\right)=1.529 \%$ \\
\hline & & $\begin{array}{l}M_{\max D K L} \\
=\{4,7,13,19,23,24,26,33,34,35,39,43,46\}\end{array}$ & $D_{K L}=10.31$ bit \\
\hline
\end{tabular}

\section{Conclusions}

The steam boiler thermal capacity and its standard uncertainty for minimum measurement information (without data reconciliation) for assumed direct measurements uncertainties $[14,18]$ equals to $\dot{Q}_{S B}=1595.0 \pm 67.2 \mathrm{MW}$. Relative standard deviation of the steam boiler thermal capacity in this case equals to $\operatorname{RSD}\left(\dot{Q}_{S B}\right)=4.213 \%$. The Table 3 contains the results of optimization calculations. Column 2 of this table shows the configuration numbers for considered additional redundant measurements. The column 3 of the Table 3 presents the sets of the optimal configurations of the redundant measurements location for optimized quantities, that are: relative standard deviation of the thermal capacity of the boiler and Kullback-Leibler divergence. The column 4 shows the values of these optimized quantities. First of all it can be concluded that the sets of redundant measurements that provide the minimum value of the relative standard deviation of the steam boiler capacity and the maximum value of the Kullback-Leibler divergence (i.e.; the minimum information entropy of the measurements) are different.

Values of the relative standard deviation of steam boiler thermal capacity in column 4 of Table 3 shows that adding only one additional redundant measurement (in this case it is flow of the feed water at the inlet of bypass heat exchanger BFWE - measurement point No. 43) causes a significant reduction of this relative standard deviation. Comparing to initial value 
(without data reconciliation), decrease of this relative standard deviation is approximately 33 percent. Further introduction of additional redundant measurements in the optimal configurations is beneficial for decreasing $\operatorname{RSD}\left(\dot{Q}_{S B}\right)$ value. However decreasing this relative standard deviations has limit for nine redundant measurements. Value of the $\operatorname{RSD}\left(\dot{Q}_{S B}\right)$ comparing to the initial value, decreases about 62 percent. Loading a higher number of redundant measurements to the steam boiler and high-pressure heat regeneration system has no further benefits from the point of view of assumed $\operatorname{RSD}\left(\dot{Q}_{S B}\right)$ optimization criterion. From column 3 in the Table 3 the optimal configuration of additional redundant measurements which provide the minimization of $\operatorname{RSD}\left(\dot{Q}_{S B}\right)$ is: 4 - flow of the re-superheated steam at the outlet of the boiler, 7 - flow of steam to the secondary superheating, 13 - flow of injection to the live steam, 14 - flow of the feed water, 23 - temperature of the condensate at the outlet of the heat exchanger RHE1, 24 - flow of the condensate at the outlet of the heat exchanger RHE1, 33 - flow of the feed water at the inlet of the desuperheater DSH, 34 - flow of the feed water in the bypass of the desuperheater DSH, 43 - flow of the feed water at the inlet of bypass heat exchanger BFWE.

An increase of the number of redundant measurements in the considered thermal system causes decrease of the entropy information of the measurements, i.e.; the increase of the Kullback-Leibler divergence (column 4 in the Table 3). However in this case, there is no certain limit value above which the increase of the value of Kullback-Leibler divergence is very low. This divergence value increases almost linearly. Developed optimization method of redundant measurement system location could be used on the stage of designing redundant measurement system for new control operation system in power units.

The aim of the carried out calculations was also to check whether the measurement values that are different from the nominal values have an influence on the location of the redundant measurements. The calculations showed that in the considered case the thermal capacity of the boiler does not have influence on the location of the redundant measurements, i.e.; for each boiler thermal capacity (in the range of 60 to $100 \%$ of nominal power unit load) the same optimal configuration of redundant measurements is being achieved.

\section{Acknowledgement}

The results presented in this paper were obtained from research work co-financed by the National Centre of Research and Development in the framework of Contract SP/E/1/67484/10 - Strategic Research Programme - Advanced technologies for obtaining energy: Development of a technology for highly efficient zero-emission coal-fired power units integrated with $\mathrm{CO}_{2}$ capture. 


\section{Nomenclature}

$D_{K L}-$ Kullback-Leibler divergence, bit,

$f_{i}(z)-i$-th criterion function,

$h$ - specific enthalpy, $\mathrm{kJ} / \mathrm{kg}$,

$k$ - current number of redundant measurement,

$L-$ number of location configurations of a redundant measurements data,

$m$ - number of measurements data,

$\dot{m}$ - mass flow, $\mathrm{kg} / \mathrm{s}$,

$n$ - number of considered redundant measurements,

$p$ - pressure, $\mathrm{Pa}$

$q$ - number of optimization criteria,

$\dot{Q}_{S B}$ - thermal capacity of the steam boiler, MW,

$r$ - number of a conditional equations,

$R S D$ - relative standard deviation,

$t$ - temperature, $\mathrm{K}$,

$u$ - number of not measured variables,

$w$ - weight of the criterion function,

$x$ - raw measurement data,

$\hat{x}$ - reconciled measurement data,

$\hat{y}$ - reconciled not measured variable,

$z$ - variable representing the solution of the optimization,

$\sigma$ - standard uncertainty of raw measurement data,

$\hat{\sigma}-$ standard uncertainty of a reconciled measurement data.

\section{References}

[1] Bagajewicz M.J.: Process Plant Instrumentation: Design and Upgrade. Technomic Publishing Company, Inc. Lancaster, Pennsylvania, USA. 2001.

[2] Chmielniak T.: Energy technologies (in Polish). WNT Publisher, Warszawa, 2013.

[3] Kullback S., Leibler R.A.: On Information and Sufficiency. Annals of Mathematical Statistics 22 (1), 1951, pp. 79-86.

[4] Rusinowski H., Stanek W.: Hybrid model of steam boiler. Energy Vol. 35 Issue 2, Feb. 2010, pp. 1107-1113.

[5] Shannon C.E.: A Mathematical Theory of Communication. The Bell System Technical Journal, Vol. 27, pp. 379-423, 623-656, July, October, 1948.

[6] Szargut J., Ziębik A.: Basics of Thermal Power Engineering. (in Polish), PWN, Warszawa 1998.

[7] Szargut J. at al.: Reconciliation Calculus in Thermal Engineering (in Polish). Polish Academy of Sciences, Ossolineum Publisher, Wrocław 1984.

[8] Szega M.: Advantages of an application of the generalized method of data reconciliation in thermal technology. Archives of Thermodynamics. Vol. 30, No. 4, (2009), pp. 219-232.

[9] Szega M.: Application of Data Reconciliation Method for Increase of Measurements Reliability in the Power Unit System of a Steam Power Plant. Monograph No. 193. Silesian University of Technology Publisher, Gliwice 2009, (in Polish).

[10] Szega M.: Application of the Entropy Information for the Optimization of an Additional Measurements Location in Thermal Systems. Archives of Thermodynamics. Vol. 32, 2011, No.3, pp. 215-229. 
[11] Valero A., Uson S.: Oxy-co-gasification of coal and biomass in an integrated gasification combined cycle (IGCC) power plant. Energy, vol. 31 (2006), 1643-1655.

[12] Verda V., Serra L., Valero A.: The effects of the control system on the thermoeconomic diagnosis of a power plant Energy, vol. 29, Issue: 3, March, 2004, pp. 331-359.

[13] Veverka V., Madron F.: Material and Energy Balancing in the Process Industries. From Microscopic Balances to Large Plants. Computer-Aided Chemical Enginnering, 7, Elsevier Science B.V. 1997.

[14] Guide to the Expression of Uncertainty in Measurement. International Organization for Standardization, 1995.

[15] Polish Standard PN-EN 12952-15. Water-tube boilers and auxiliary installations - Part 15: Acceptance tests. (in Polish). PKN Warszawa, 2006.

[16] Thermoflow, Inc., 29 Hudson Road, Sudbury, MA 01776 USA, http://www.thermoflow.com

[17] VDI-Richtlinien.: Messunsicherheiten bei Abnahmemessungen an Energie - und kraftwerkstechnischen Anlagen, Grundlagen, VDI 2048, Blatt 1. Oktober 1998.

[18] VDI-Richtlinien.: Messunsicherheiten bei Abnahmemesungen an energie- und kraftwerkstechnischen Anlagen, Beispiele, VDI 2048, Blatt 2. Dezember 2001. 


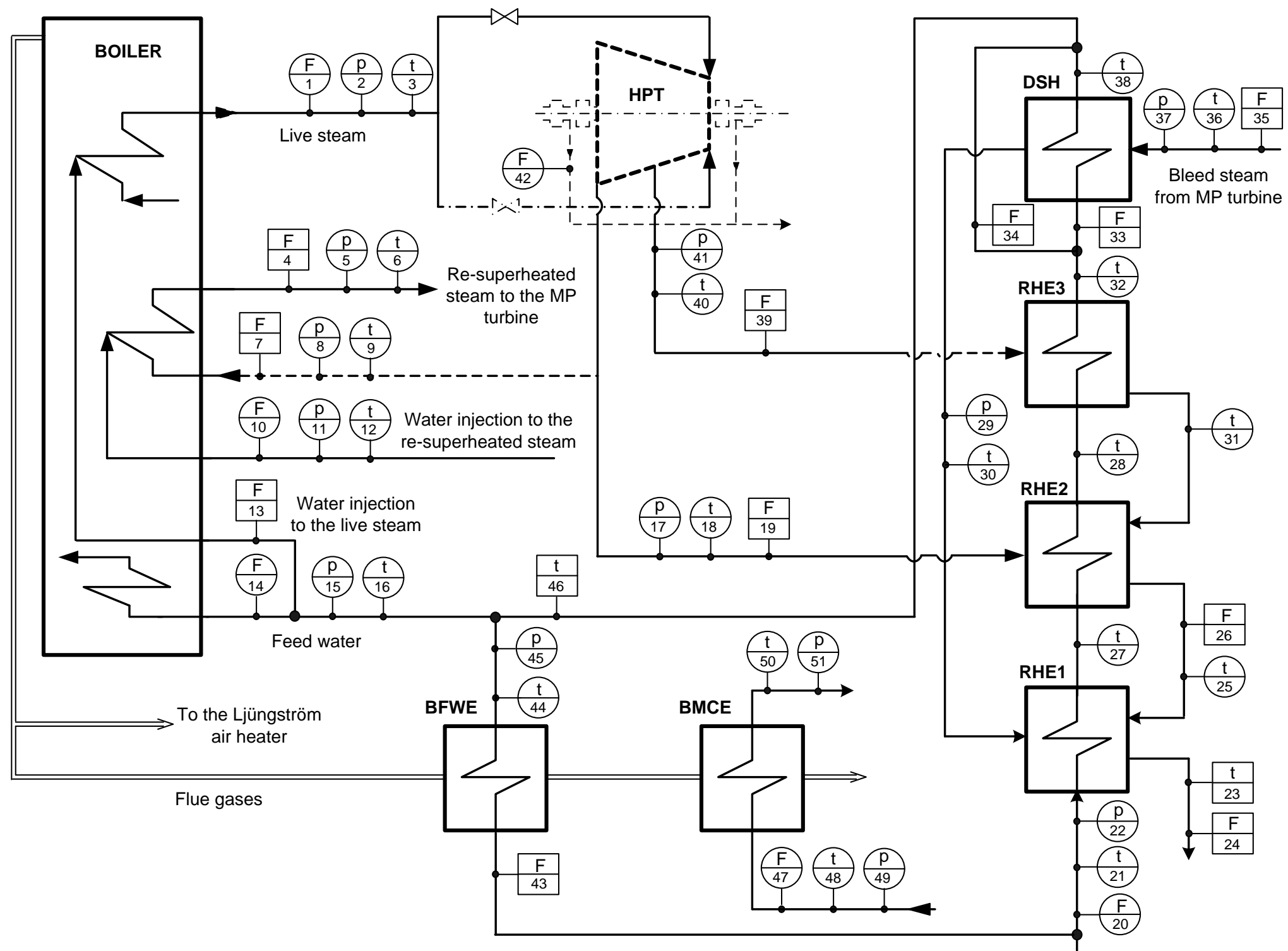

Fig. 1. Scheme of the considered thermal system of the boiler, high pressure part of the steam turbine and high pressure heat regeneration system 